
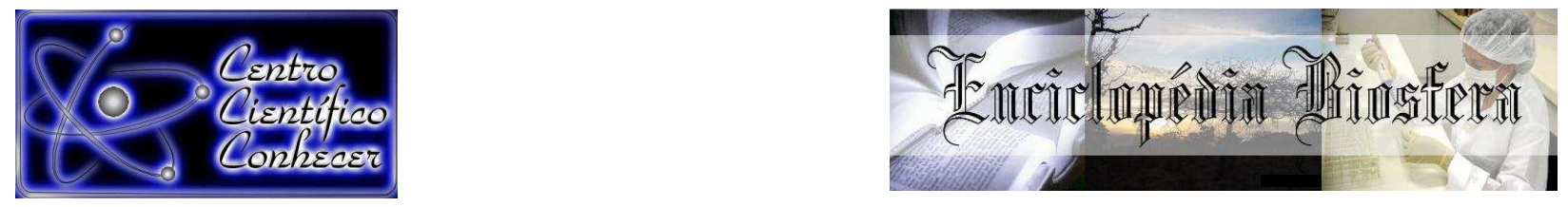

\title{
ABRANGÊNCIA DA DECLARAÇÃO DE APTIDÃO AO PRONAF (DAP) E DO PROGRAMA GARANTIA SAFRA 2015/2016 AOS AGRICULTORES FAMILIARES DO TERRITÓRIO DE IDENTIDADE SUDOESTE BAIANO
}

Douglas Gonçalves Guimarães ${ }^{1}$; Carla Simone Araújo Gomes Sarmento²; Eduardo Barreto de Castro Filho ${ }^{3}$

${ }^{1}$ Bacharel e MSc em Engenharia Agronômica pela Universidade Estadual do Sudoeste da Bahia - UESB e Técnico de Nível Superior da Superintendência Baiana de Assistência Técnica e Extensão Rural - BAHIATER. (douglasgg@hotmail.com), Vitória da Conquista - Brasil.

${ }^{2}$ Bacharel em Engenharia Agronômica pela Universidade Estadual do Sudoeste da Bahia - UESB e Técnica de Nível Superior Coordenação de Desenvolvimento Agrário - CDA

${ }^{3}$ Bacharel em Engenharia Agronômica pela Universidade Estadual do Sudoeste da Bahia - UESB e Técnico de Nível Superior da Superintendência Baiana de Assistência Técnica e Extensão Rural - BAHIATER

Recebido em: 08/04/2016 - Aprovado em: 30/05/2016 - Publicado em: 20/06/2016 DOI: 10.18677/Enciclopedia_Biosfera_2016_003

\section{RESUMO}

Com o objetivo de analisar a abrangência da DAP e do Programa Garantia Safra entre os agricultores familiares do Território de Identidade Sudoeste Baiano foi realizado este artigo. Os dados foram oriundos dos sítios eletrônicos do IBGE e do MDA, foram analisados população rural, estabelecimentos agropecuários oriundas da agricultura familiar, número de DAPs ativas, número de aderidos no Garantia Safra 2015/16, proporção de DAPs e de aderidos no Garantia Safra pelo número de estabelecimentos agropecuários da agricultura familiar e proporção de aderidos no Garantia Safra pelo número de DAPs ativas nos municípios de Anagé, Aracatu, Barra do Choça, Belo Campo, Bom Jesus da Serra, Caetanos, Cândido Sales, Caraíbas, Condeúba, Cordeiros, Encruzilhada, Guajerú, Jacaraci, Licínio de Almeida, Maetinga, Mirante, Mortugaba, Piripá, Planalto, Poções, Presidente Jânio Quadros, Ribeirão do Largo, Tremedal e Vitória da Conquista. Considerando o número de estabelecimentos agropecuários pertencentes a agricultura familiar: Planalto, Bom Jesus da Serra e Cândido Sales se destacaram em número de DAPs, enquanto Encruzilhada, Caraíbas e Mortugaba apresentaram os menores valores. Bom Jesus da Serra, Planalto e Poções apresentaram os maiores valores proporcionais de agricultores aderidos no Programa Garantia Safra 2015/16 e os menores valores ficaram com os municípios de Encruzilhada, Ribeirão do Largo e Barra do Choça. Pesquisas mais detalhadas devem ser realizadas com o intuito de se constatar com mais clareza e realidade os valores de agricultores desassistidos pelas politicas públicas do meio rural, afim de melhorias na agricultura familiar.

PALAVRAS-CHAVE: Agricultura Familiar, Desenvolvimento Rural, Políticas Públicas. 


\title{
SCOPE OF THE DECLARATION OF FITNESS FOR PRONAF (DAP) AND GARANTIA SAFRA PROGRAM 2015/2016 FARMERS FAMILY OF TERRITORY OF IDENTITY SUDOESTE BAIANO
}

\begin{abstract}
In order to analyze the scope of DAP and Program Garantia Safra among family farmers of Territory of Identity Sudoeste Baiano was held this Article. Data were derived from electronic sites of IBGE and MDA, were analyzed rural population, agricultural establishments derived from family farming, number of active DAPs, number accession in Garantia Safra 2015/16, proportion of DAPs and accession in Garantia Safra by the number of farms in the family farming and proportion of accession in Garantia Safra by the active number of DAPs in the municipalities of Anagé, Aracatu, Barra do Choça, Belo Campo, Bom Jesus da Serra, Caetanos, Cândido Sales, Caraíbas, Condeúba, Cordeiros, Encruzilhada, Guajerú, Jacaraci, Licínio de Almeida, Maetinga, Mirante, Mortugaba, Piripá, Planalto, Poções, Presidente Jânio Quadros, Ribeirão do Largo, Tremedal and Vitória da Conquista. Considering the number of agricultural establishments belonging to family farming: Planalto, Bom Jesus da Serra and Cândido Sales stood out in number of DAPS, while Encruzilhada, Caraíbas and Mortugaba had the lowest values. Bom Jesus da Serra, Planalto and Poções have the highest proportional values attached farmers Garantia Safra Program 2015/16 and the lowest values were the municipalities of Encruzilhada, Ribeirão do Largo and Barra do Choça. More detailed research should be conducted in order to be seen more clearly and reality farmers values underserved by the public policies of the countryside in order to improvements in family farming.
\end{abstract}

KEYWORDS: Family Farming, Rural Development, Public Policy.

\section{INTRODUÇÃO}

A agricultura familiar cria, inova, produz e também alimenta o País. Os mais de quatro milhões de estabelecimentos familiares distribuídos entre os 26 estados e - Distrito Federal alimentam a população nacional e movimentam a economia brasileira, sendo responsável por 33\% do Produto Interno Bruto (PIB) Agropecuário e 74\% da mão de obra empregada no campo. Em apenas dez anos, a renda do setor cresceu $52 \%$ a partir de políticas públicas que fortalecem a produção e 0 desenvolvimento (MDA, 2014).

O estado da Bahia, segundo os últimos dados do Instituto Brasileiro de Geografia e Estatísticas (IBGE), realizado em 2006, é o estado que apresenta maior número de estabelecimentos agropecuários referentes a agricultura familiar, com quase 700 mil unidades. Com relação a população rural, em 2010 o estado tinha cerca de quatro milhões de pessoas residentes em zonas rurais, o que também colocou a Bahia como o estado com maior número de pessoas que vivem no meio rural, sendo consequentemente o estado com maior número de agricultores familiares do Brasil (IBGE, 2016).

Assim como no país, o Estado da Bahia e seus municípios ressentiram-se da ausência de políticas regionais nacionais e estaduais, resultando com o avanço das desigualdades regionais e no caso da Bahia houve a divisão do Estado em territórios de Identidade onde, a conceituação de "território" originou-se no Ministério de Desenvolvimento Agrário (MDA), assim, a divisão da Bahia foi implantada em 2007 pela Superintendência de Estudos Econômicos e Sociais da Bahia (SEI) vinculada à 
Secretaria de Planejamento do Estado da Bahia (SEPLAN), inserindo-se os 417 municípios baianos em 27 territórios atualmente (BLATT \& GONDIM, 2013).

O Programa Territórios de Identidade foi instituído pelo Decreto 12.354, de 25 de agosto de 2010, com funções como promover o desenvolvimento econômico e social dos Municípios do Estado da Bahia, segundo este Decreto, considera-se Território de Identidade o agrupamento identitário municipal formado de acordo com critérios sociais, culturais, econômicos e geográficos, reconhecido pela sua população como o espaço historicamente construído ao qual pertence, com identidade que amplia as possibilidades de coesão social e territorial (BAHIA, 2010).

O Território de Identidade Vitória da Conquista, recentemente teve seu nome substituído por Território de Identidade Sudoeste Baiano, entretanto, não houve mudanças nos municípios abrangidos, continuou com os mesmos 24 municípios, território este, que conta com um número considerável de cidadãos enquadrados como agricultores familiares. Segundo a legislação brasileira, considera-se agricultor familiar, aquele que pratica atividades no meio rural, que não detenha área maior que quatro módulos fiscais, utilize predominantemente mão-de-obra da própria família nas atividades econômicas do seu estabelecimento, tenha percentual mínimo da renda familiar originada de atividades econômicas do seu estabelecimento, na forma definida pelo Poder Executivo e dirija o estabelecimento ou empreendimento com sua família (BRASIL, 2006, 2011).

Em 28 de junho de 1996, foi assinado o Decreto № 1.946, que criou o Programa Nacional de Fortalecimento da Agricultura Familiar (PRONAF), com a finalidade de promover o desenvolvimento sustentável do segmento rural constituído pelos agricultores familiares, de modo a propiciar-lhes o aumento da capacidade produtiva, a geração de empregos e a melhoria de renda (BRASIL, 1996), e a partir da Portaria no 386, de 24/09/1997 foi criada a declaração de aptidão (DAP), que é a verificação de enquadramento do agricultor no perfil designado como agricultor familiar (ABRAMOVAY \& VEIGA, 1998).

A Declaração de Aptidão ao PRONAF (DAP), é um documento de identificação do agricultor familiar, no qual a unidade familiar cadastrada passa a ter direito de acessar políticas públicas. O agricultor familiar que se enquadra nas normas vigentes deve procurar uma entidade credenciada junto ao Ministério do Desenvolvimento Agrário (MDA) que tem o poder de emitir este documento. Com o documento em mãos, o agricultor familiar passa a poder acessar diversos programas do governo federal, como financiamento com baixas taxas de juros, participar do Programa de Aquisição de Alimentos (PAA), Programa Garantia Safra, dentre outros.

A lei № 10.420 , de 10 de abril de 2002, criou o Fundo Garantia Safra e instituiu o benefício Garantia Safra (alterada pela Lei № 12.766/2012), com o objetivo de garantir condições mínimas de sobrevivência aos agricultores familiares de Municípios sistematicamente sujeitos a perda de safra por razão do fenômeno da estiagem ou excesso hídrico. Tem direto ao Benefício Garantia Safra os agricultores familiares cuja renda bruta familiar mensal não exceda a 1,5 salários mínimos, que aderiram ao Fundo Garantia Safra e sofreram perdas em razão de estiagem ou excesso hídrico, comprovada na forma do regulamento, de pelo menos $50 \%$ do conjunto da produção de feijão, milho, arroz, mandioca ou algodão (BRASIL, 2002, 2012).

O programa começou atuar no estado da Bahia na safra 2007/2008 e no Território de Identidade Sudoeste Baiano nos municípios de Condeúba, Cordeiros, 
Licínio de Almeida e Poções na safra 2009/2010 e em ambos teve um considerável aumento no número de novas adesões de municípios e agricultores a cada ano desde então (MDA, 2016). O Programa ajuda a manter o produtor no campo, incentivando a continuidade do trabalho agrícola em suas propriedades e auxiliando na renda do agricultor familiar, visto que devido a eventos climáticos a maioria das produções agrícolas decresceram nos últimos anos e sem noticias animadoras para o futuro, pesquisadores em recentes estudos têm estimado que cultivos de subsistência, como feijão, milho e mandioca poderão sofrer diminuição acentuada de produtividade nos cenários de mudanças climáticas (LOBELL et al., 2008; MARGULIS et al., 2010). Para MARTINS et al. (2014), as atuais perdas na produção agrícola que vem ocorrendo nos últimos anos são preocupantes para todas as nações e requerem ações rápidas para evitar que os prejuízos econômicos e sociais sejam recorrentes.

O objetivo do presente estudo foi analisar a abrangência do documento que identifica o agricultor familiar, a DAP, e um dos principais programas voltados para a população rural da região, que é o Programa Garantia Safra, durante a safra 2015/2016, no Território de Identidade Sudoeste Baiano, a fim de tentar obter respostas sobre como o agricultor familiar desta região está sendo assistido pelos órgãos competentes e assim melhorar a inclusão destes e de outros programas ao agricultor familiar local, melhorando sua atividade agrícola e consequentemente sua vida e de toda sua família.

\section{MATERIAL E MÉTODOS}

O presente trabalho foi realizado analisando dados do Território de Identidade Sudoeste Baiano, anteriormente denominado de Território de Identidade Vitória da Conquista, que é um dos 27 territórios de identidade do Estado da Bahia e que abrange 24 municípios: Anagé, Aracatu, Barra do Choça, Belo Campo, Bom Jesus da Serra, Caetanos, Cândido Sales, Caraíbas, Condeúba, Cordeiros, Encruzilhada, Guajerú, Jacaraci, Licínio de Almeida, Maetinga, Mirante, Mortugaba, Piripá, Planalto, Poções, Presidente Jânio Quadros, Ribeirão do Largo, Tremedal e Vitória da Conquista (Figura 1).

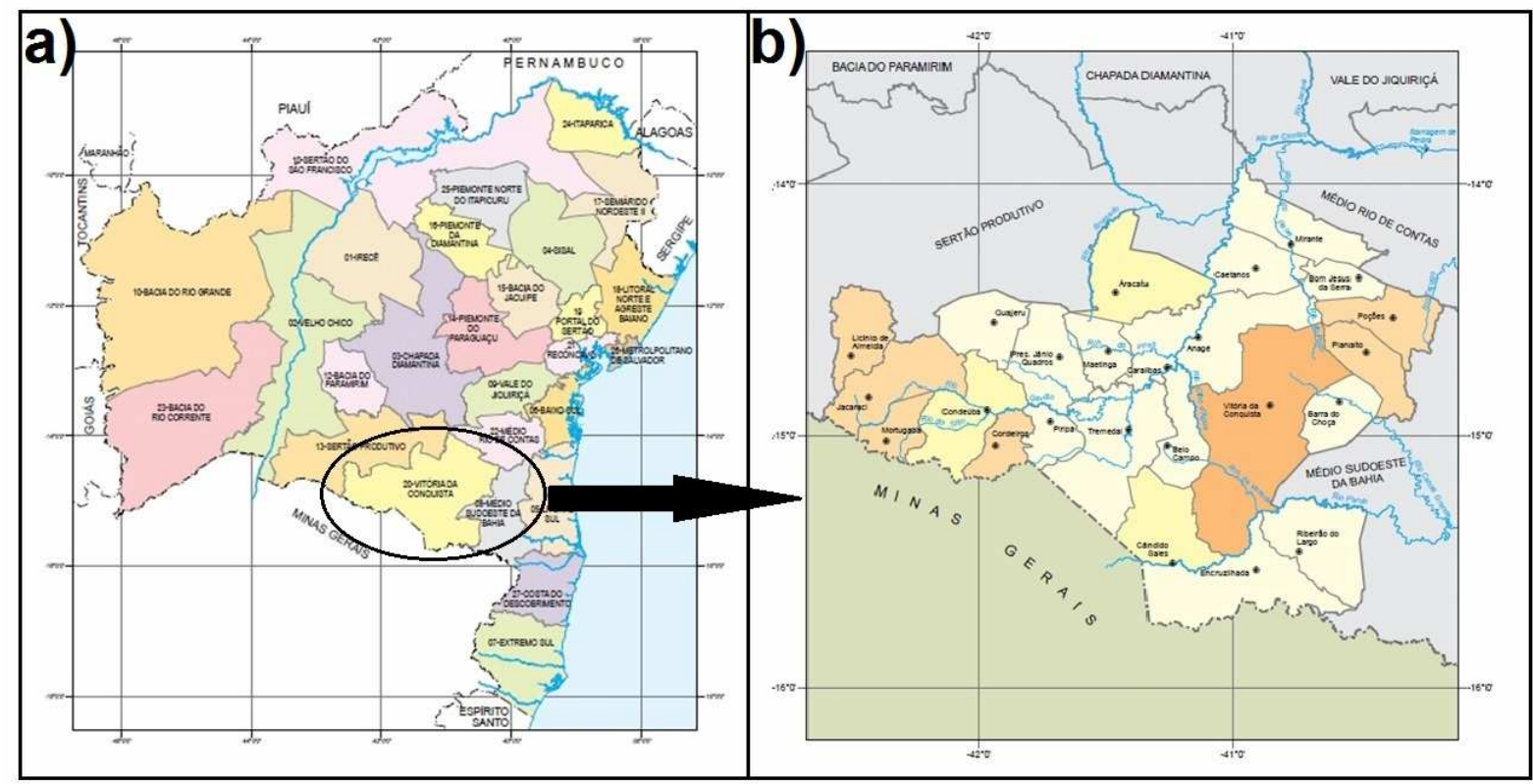

FIGURA 1. Mapa da Bahia com as divisões dos territórios de Identidade (a) e mapa do território de Identidade Sudoeste Baiano (Vitória da Conquista) com a divisão dos municípios (b).

Fonte: Superintendência de Estudos Econômicos e Sociais da Bahia - SEI. 
Segundo dados de 2010, o Território de Identidade Sudoeste Baiano abrange uma população de quase 700 mil habitantes, sendo que destes, 244.991 habitantes são residentes da zona rural, Vitória da Conquista é o município com maior população, cerca de 306 mil habitantes, o menos populoso é Maetinga, com pouco mais de 7 mil habitantes, a área total é de cerca de 27 mil quilômetros quadrados (IBGE, 2016).

A altitude média dos municípios do Território varia de 943 metros de altitude em Planalto a 384 metros observados em Anagé e Mortugaba, o período chuvoso varia de acordo com os municípios, mas entre os meses de outubro a abril, com média de precipitação anual variando de 976,1 $\mathrm{mm}$ em Encruzilhada a 339,1 $\mathrm{mm}$ em Maetinga e Presidente Jânio Quadros (EMB, 2013).

Os dados para construção e posterior discussão do artigo foram obtidos de órgãos do Governo Federal. Os dados de estabelecimentos rurais enquadrados na agricultura familiar foram do censo agropecuário do ano de 2006 e os números de residentes da zona rural são referentes ao censo demográfico 2010, ambos foram disponíveis através de consulta ao sitio eletrônico do Banco de Dados Agregados do Sistema do Instituto Brasileiro de Geografia e Estatísticas (IBGE) de Recuperação automática - SIDRA.

Para o número de Declarações de Aptidão ao PRONAF (DAPs) Ativas foi consultado "Pesquisa de DAPs Ativas por município" e para obtenção dos dados de aderidos no Garantia Safra 2015/2016 foi pesquisado na aba "Relatórios Públicos de Implementação do Garantia Safra". Os dois dados estão disponíveis no sitio eletrônico do Ministério do Desenvolvimento Agrário (MDA).

A partir destes dados citados acima foi obtida a proporção de DAPs ativas e aderidos no Programa Garantia Safra 2015/2016 pelo número de estabelecimentos agropecuários da agricultura familiar e também a porcentagem de aderidos no Garantia Safra pelo número de DAPs Ativas, efetuando a divisão dos valores.

A experiência profissional dos autores também serviu como auxilio na compreensão e interpretação dos dados, visto que estes são extensionistas da Secretaria de Desenvolvimento Rural - SDR e que prestam serviço no Serviço Territorial de Apoio à Agricultura Familiar (SETAF) do Território de Identidade Sudoeste Baiano, atuando diretamente nos 24 municípios estudados, realizando, entre outros trabalhos, no caso específico da BAHIATER, emitindo DAPs e inscrições do Programa Garantia Safra aos agricultores familiares do Território.

\section{RESULTADOS E DISCUSSÃO}

Apesar do número de estabelecimentos rurais ocupados por agricultores enquadrados na agricultura familiar divulgados pelo IBGE não serem relativamente recentes e que podem estar desatualizados, estes dados, juntamente com a quantidade da população rural, servem de base para constatação quantitativa do real valor destes números. Estes dados, comparados com os dados atuais de número de DAPs ativas e de aderidos no Programa Garantia Safra podem servir de base para avaliação de como as políticas públicas rurais estão sendo desenvolvidas em determinadas regiões. A partir de uma análise minuciosa, não só com os números, mas também com o conhecimento de causa e experiência técnica, podese constatar quais municípios apresentam agricultores familiares que estão mais desassistidos pelos Programas do Governo Federal e assim tentar solucionar este problema, garantindo assistência técnica para todos. 
$\mathrm{Na}$ Tabela 1 são apresentados dados com valores absolutos dos produtores rurais do Território de Identidade Sudoeste Baiano. Constata-se nesta Tabela, que os municípios que apresentam maiores populações rurais são Vitória da Conquista, Anagé e Encruzilhada, municípios estes com maiores extensões territoriais e os municípios que possuem mais estabelecimentos agropecuários da agricultura familiar foram Vitória da Conquista, Anagé e Tremedal. O número de DAPs ativas variaram de 4.323 em Vitória da Conquista a 948 em Barra do Choça, com total no Território de 44.718. Com relação ao número de aderidos no Programa Garantia Safra 2015/16, ou seja, aqueles agricultores que fizeram a inscrição, foram aprovados pelos respectivos Conselhos Municipais de Desenvolvimento Sustentável (CMDS) e que pagaram o boleto, resultaram em 23.520 agricultores, com Anagé sendo o que teve mais aderidos (1.854) e Barra do Choça que apresentou menos adesão (37).

TABELA 1. População rural, número de estabelecimentos agropecuários da agricultura familiar (AF), número de DAPs ativas e quantidade de famílias aderidas no Programa Garantia Safra 2015/2016 dos municípios do Território de Identidade Sudoeste Baiano.

\begin{tabular}{|c|c|c|c|c|}
\hline \multirow[b]{2}{*}{ Municípios } & \multicolumn{4}{|c|}{ Dados dos Produtores Rurais do Território } \\
\hline & $\begin{array}{c}\text { População } \\
\text { Rural }^{1}\end{array}$ & $\begin{array}{c}\text { Estabelecimentos } \\
\text { Agropecuários } \\
(\mathrm{AF})^{2}\end{array}$ & $\begin{array}{c}\text { DAPs } \\
\text { Ativas }^{3}\end{array}$ & $\begin{array}{c}\text { Aderidos no } \\
\text { Garantia Safra } \\
2015 / 2016^{4}\end{array}$ \\
\hline Anagé & 20.592 & 2.835 & 2.936 & 1.854 \\
\hline Aracatu & 9.805 & 2.297 & 2.904 & 1.680 \\
\hline Barra do Choça & 12.381 & 1.028 & 948 & 37 \\
\hline Belo Campo & 6.992 & 1.143 & 1.126 & 297 \\
\hline Bom Jesus da Serra & 7.345 & 1.070 & 1.986 & 1.244 \\
\hline Caetanos & 10.348 & 1.850 & 2.277 & 1.445 \\
\hline Cândido Sales & 8.632 & 614 & 1.136 & 512 \\
\hline Caraíbas & 7.709 & 1.752 & 1.047 & 706 \\
\hline Condeúba & 9.436 & 1.658 & 2.243 & 1.399 \\
\hline Cordeiros & 5.617 & 1.090 & 1.375 & 897 \\
\hline Encruzilhada & 18.636 & 1.295 & 826 & 173 \\
\hline Guajeru & 8.335 & 1.177 & 1.335 & 760 \\
\hline Jacaraci & 8.728 & 2.116 & 2.413 & 1.848 \\
\hline Licínio de Almeida & 6.058 & 1.454 & 1.729 & 1.170 \\
\hline Maetinga & 4.221 & 904 & 1.101 & 813 \\
\hline Mirante & 8.698 & 1.019 & 1.440 & 587 \\
\hline Mortugaba & 6.590 & 2.145 & 1.172 & 721 \\
\hline Piripá & 6.588 & 1.175 & 1.353 & 810 \\
\hline Planalto & 9.612 & 970 & 1.833 & 945 \\
\hline Poções & 10.042 & 1.940 & 2.995 & 1.774 \\
\hline $\begin{array}{l}\text { Presidente Jânio } \\
\text { Quadros }\end{array}$ & 9.454 & 2.503 & 2.805 & 1.178 \\
\hline Ribeirão do Largo & 3.955 & 745 & 1.173 & 68 \\
\hline Tremedal & 13.090 & 2.653 & 2.242 & 1.265 \\
\hline Vitória da Conquista & 32.127 & 3.085 & 4.323 & 1.337 \\
\hline TOTAL & 244.991 & 38.518 & 44.718 & 23.520 \\
\hline $\begin{array}{l}\text { IBGE (2010). Disponí } \\
{ }^{2} \text { IBGE (2006). Disponí } \\
{ }^{3} \mathrm{MDA}(2016) \text {. Acesso } \\
\text { http://smap14.mda.go }\end{array}$ & $\begin{array}{l}\mathrm{m}:(\mathrm{http}: / / \text { www.si } \\
\mathrm{m}: \text { (http://www.si } \\
1 \text { de fevereiro de } \\
\text { extratopf/Pesqui }\end{array}$ & $\begin{array}{l}\text { ra.ibge.gov.br/bda/tabela } \\
\text { ra.ibge.gov.br/bda/tabela } \\
\text { 2016, disponível em: } \\
\text { Municipio.aspx) }\end{array}$ & $\begin{array}{l}\text { bl.asp? } z=t 8 \\
\text { bl.asp?c=1 }\end{array}$ & $\frac{25 \& \mathrm{i}=\mathrm{P} \& \mathrm{C}=1378)}{\& \mathrm{z}=\mathrm{p} \& \mathrm{O}=2 \& \mathrm{i}=\mathrm{P})}$ \\
\hline
\end{tabular}


A cidade de Vitória da Conquista é um grande centro urbano regional, considerando dados de 2010 do IBGE, é o terceiro município mais populoso da Bahia e que abrange $44 \%$ da população do Território Sudoeste Baiano, todavia, apenas $10,5 \%$ da população é residente da zona rural, excetuando-se este município, mais os municípios de Poções, com $22,5 \%$ da população na zona rural, Cândido Sales $(30,9 \%)$, Barra do Choça $(35,6 \%)$, Planalto $(39,3 \%)$, Belo Campo (43,6\%), Ribeirão do Largo (46\%) e Licínio de Almeida (49,2\%), todos os outros 16 municípios do território tem população predominantemente rural, sete destes com população rural acima de $70 \%$ do total: Aracatu (71,3\%), Bom Jesus da Serra $(72,6 \%)$, Caraíbas $(75,4 \%)$, Caetanos $(75,9 \%)$, Tremedal (76,9\%), Encruzilhada (78,4\%), Guajeru (80,1\%), Anagé (80,7\%) e Mirante (82,8\%) (IBGE, 2016).

Constatando esses dados, percebe-se a importância do produtor rural na economia destes municípios, influenciando consideravelmente na economia local. Assim, programas que melhorem as condições de vida, consequentemente atingirá positivamente todo município, incluindo os residentes nas zonas urbanas. Segundo GUILHOTO et al. (2007), 10\% do Produto Interno Bruto (PIB) nacional resulta da agricultura familiar.

Como observado na Tabela 1, no Território Sudoeste Baiano, um total de 23.520 famílias de agricultores familiares que possuem DAP e que possuem uma renda mensal de até 1,5 salários mínimos estão aderidos no Programa Garantia Safra 2015/16, estes produtores, que terão que plantar uma área de 0,6 a 5 hectares das culturas abrangidas pelo programa, posteriormente caso seja constatado perda da safra de pelo menos $50 \%$, em razão de estiagem ou excesso hídrico, comprovada na forma do regulamento, receberão a quantia, referente a esta safra, cinco parcelas de $R \$ 170,00$, resultando em $R \$ 850,00$ por família aderida. Caso seja constatada perda em todos os municípios do Território e se nenhum destes produtores forem desclassificados, entrará na economia desta região, o total de $R \$$ 19.992.000,00, influenciando consideravelmente a vida de milhares de pessoas.

A perda de safra se confirmando, os produtores dos municípios com maiores adesões nesta safra, que foram Anagé, Jacaraci e Poções receberão $R \$$ $1.575 .900,00, R \$ 1.570 .800,00$ e $1.507 .900,00$, respectivamente. Em contrapartida, os agricultores familiares dos municípios com menores adesões, receberão, na somatória, um valor bem abaixo, Encruzilhada receberá $R \$ 147.050,00$, Ribeirão do Largo a quantia de $\mathrm{R} \$ 57.800,00$ e em Barra do Choça, os agricultores aderidos, juntos receberão apenas $R \$ 31.450,00$.

Em números absolutos fica mais difícil mensurar quais municípios estão em melhores condições quanto ao número de agricultores familiares participantes destes programas. Para facilitar a interpretação, na Tabela 2 são apresentados os valores proporcionais de DAPs Ativas e aderidos no Programa Garantia Safra 2015/16 pelo número de estabelecimentos agropecuários da agricultura familiar e a proporção de aderidos no Garantia Safra 2015/16 pelo número de DAPs Ativas. 
TABELA 2. Proporção de DAPs Ativas (\% de DAPs) e de aderidos no Programa Garantia Safra 2015/16 (\% de AGS) pelo número de estabelecimentos agropecuários da agricultura familiar (NEA-AF) e proporção de aderidos no Programa Garantia Safra 2015/16 pelo número de DAPs Ativas (AGS/DAPs) dos municípios do Território de Identidade Sudoeste Baiano.

\begin{tabular}{lrrr}
\hline \multirow{2}{*}{ Municípios } & \multicolumn{2}{c}{ Proporção pelo NEA-AF } & \\
\cline { 2 - 3 } & \% de DAPs & $\%$ de AGS & AGS/DAPs \\
\hline Anagé & $103,6 \%$ & $65,4 \%$ & $63,1 \%$ \\
\hline Aracatu & $126,4 \%$ & $73,1 \%$ & $57,9 \%$ \\
\hline Barra do Choça & $92,2 \%$ & $3,6 \%$ & $3,9 \%$ \\
\hline Belo Campo & $98,5 \%$ & $26,0 \%$ & $26,4 \%$ \\
\hline Bom Jesus da Serra & $185,6 \%$ & $116,3 \%$ & $62,6 \%$ \\
\hline Caetanos & $123,1 \%$ & $78,1 \%$ & $63,5 \%$ \\
\hline Cândido Sales & $185,0 \%$ & $83,4 \%$ & $45,1 \%$ \\
\hline Caraíbas & $59,8 \%$ & $40,3 \%$ & $67,4 \%$ \\
\hline Condeúba & $135,3 \%$ & $84,4 \%$ & $62,4 \%$ \\
\hline Cordeiros & $126,1 \%$ & $82,3 \%$ & $65,2 \%$ \\
\hline Encruzilhada & $63,8 \%$ & $13,4 \%$ & $20,9 \%$ \\
\hline Guajeru & $113,4 \%$ & $64,6 \%$ & $56,9 \%$ \\
\hline Jacaraci & $114,0 \%$ & $87,3 \%$ & $76,6 \%$ \\
\hline Licínio de Almeida & $118,9 \%$ & $80,5 \%$ & $67,7 \%$ \\
\hline Maetinga & $121,8 \%$ & $89,9 \%$ & $73,8 \%$ \\
\hline Mirante & $141,3 \%$ & $57,6 \%$ & $40,8 \%$ \\
\hline Mortugaba & $54,6 \%$ & $33,6 \%$ & $61,5 \%$ \\
\hline Piripá & $115,1 \%$ & $68,9 \%$ & $59,9 \%$ \\
\hline Planalto & $189,0 \%$ & $97,4 \%$ & $51,6 \%$ \\
\hline Poções & $154,4 \%$ & $91,4 \%$ & $59,2 \%$ \\
\hline Presidente Jânio Quadros & $112,1 \%$ & $47,1 \%$ & $42,0 \%$ \\
\hline Ribeirão do Largo & $157,4 \%$ & $9,1 \%$ & $5,8 \%$ \\
\hline Tremedal & $84,5 \%$ & $47,7 \%$ & $56,4 \%$ \\
\hline Vitória da Conquista & $140,1 \%$ & $43,3 \%$ & $30,9 \%$ \\
\hline TOTAL & $\mathbf{1 1 6 , 1 \%}$ & $\mathbf{6 1 , 1} \%$ & $\mathbf{5 2 , 6 \%}$ \\
\hline
\end{tabular}

$\mathrm{Na}$ Tabela 2 é apresentada a proporção de DAPs ativas pelo número de estabelecimentos agropecuários da agricultura familiar e observa-se que dos 24 municípios do Território, 18 apresentam mais DAPs ativas que estabelecimentos agropecuários da agricultura familiar, com municípios como Planalto, Bom Jesus da Serra, Cândido Sales, Ribeirão do Largo e Poções passando da faixa de $150 \%$. Esta disparidade dos dados pode ser atribuída a vários motivos, pode ter ocorrido que outras propriedades que anteriormente não se enquadravam como pertencentes a agricultura familiar, terem passado a esta forma, outra possível explicação seria pela venda e consequente fragmentação de propriedades desde o último censo realizado e também pelo fato de que a DAP não é um documento exclusivo para proprietários da terra, este também pode ser emitido para arrendatários, comodatários, parceiros, etc. Observa-se em muitos casos que quando os filhos formam uma família, os pais passam para esta nova unidade familiar uma parte da propriedade em forma de comodato, ou por outros meios, dando assim o direito deles terem sua própria área de cultivo e criação e podendo assim ter sua própria DAP.

Este incentivo de permanência das famílias mais jovens no campo, tendo a terra, com DAP e podendo participar das politicas públicas dos quais tem direito é muito importante para evitar o crescente êxodo rural dos jovens. FOGUESATTO \& MACHADO (2015), observaram em seu trabalho um desinteresse dos jovens em 
permanecer no campo dando seguimento nas atividades realizadas pelos seus pais e que buscas por melhores condições socioeconômicas foram relevantes para que os processos de urbanização se intensificassem. No período analisado por estes autores, de 1970 a 2010, eles constataram que a população jovem no campo decresceu quase $30 \%$, enquanto que a urbana quase que triplicou. Observando a primeira coluna da Tabela 2, observa-se também que apenas os municípios de Belo Campo, Barra do Choça, Tremedal, Encruzilhada, Caraíbas e Mortugaba não igualaram ou superaram o número de DAPs pelo número de estabelecimentos agropecuários da agricultura familiar.

Proporcionalmente, os municípios com maiores adesões no Programa Garantia Safra 2015/16 foram Bom Jesus da Serra, Planalto, Poções, Maetinga, Jacaraci, Condeúba, Cândido Sales, Cordeiros e Licínio de Almeida, todos estes com mais de $80 \%$ de adesões, quando comparados sua proporção com o número de estabelecimentos agropecuários de agricultores familiares, por outro lado, Barra do Choça, Ribeirão do Largo, Encruzilhada, Belo Campo e Mortugaba tiveram menos de $40 \%$ de agricultores familiares aderidos ao Programa (Tabela 2).

Nem todo agricultor familiar com DAP tem direito a adesão no Programa Garantia Safra, para isto, precisa atender alguns requisitos, como plantar as culturas selecionadas pelo programa e não possuir mais de 1,5 salários mínimos mensais. $\mathrm{Na}$ comparação dos municípios que proporcionalmente tiveram mais adesões pelo número de DAPs, observa-se na terceira coluna da Tabela 2 que Jacaraci $(76,6 \%)$, Maetinga (73,8\%), Licínio de Almeida (67,7\%), Caraíbas $(67,4 \%)$, Cordeiros $(65,2 \%)$, Caetanos (63,5\%), Bom Jesus da Serra $(62,6 \%)$, Condeúba $(62,4 \%)$ e Mortugaba $(61,5 \%)$ tiveram mais agricultores com DAPs aderidos no Garantia Safra.

Praticamente todos os agricultores familiares aderidos no Programa Garantia Safra do presente Território declararam plantar feijão e milho e outros poucos declararam que irão plantar mandioca nesta safra, principalmente agricultores do município de Cândido Sales, que segundo dados do IBGE de 2014 é o maior produtor de mandioca da Bahia (IBGE, 2016). As outras culturas abrangidas pelo programa, arroz e algodão praticamente não foram citadas no momento da inscrição, os agricultores da maioria dos municípios do Território não fazem o plantio destas culturas, principalmente no caso específico do arroz.

Os municípios situados geograficamente mais a Leste do Território, numa zona de transição de Mata Atlântica e mais próximo do litoral, como Barra do Choça, Vitória da Conquista, Planalto, Encruzilhada, Poções e Ribeirão do Largo estão entre os vinte e três maiores produtores de café arábica da Bahia (IBGE, 2016), cultura que não esta aderida no Programa Garantia Safra. O fato de parte dos estabelecimentos rurais destes municípios serem utilizados para o plantio de café, por grandes e até mesmo por pequenos produtores, pode ser uma explicação para a relativa baixa adesão destes municípios no programa Garantia Safra comparada com o número de DAPs, em que muitos agricultores familiares destes municípios deixam de plantar as culturas subsidiadas pelo Garantia Safra para cuidar do cultivo de café. É observado também que com a plantação de café a renda geralmente tende a ficar mais alta, acima de 1,5 salários mínimos mensais, ficando impossibilitados de participarem do Programa.

Até os municípios de Poções e Planalto, que apresentaram um número alto de aderidos no Programa Garantia Safra considerando números absolutos (Tabela 1), quando a comparação de aderidos no Garantia Safra foi com base no número de DAPs ativas não passaram de $60 \%$ (Tabela 2), comportamento semelhante foi 
observado nos outros municípios produtores de café. Esta observação fica mais evidente quando analisa-se os dados de Barra do Choça, município com menor adesão de agricultores no programa Garantia Safra 2015/16, em números absolutos e proporcionais (Tabelas 1 e 2), mas é com larga vantagem, o município com maior produção de café arábica da Bahia (IBGE, 2016), cultura esta que corresponde a 83\% da atividade econômica e da ocupação da mão de obra deste município (MEIRA et al., 2013).

Os demais municípios do Território, mais a oeste e que apresentam condições edafoclimáticas menos favoráveis para o cultivo de café e outras culturas, que geralmente apresentam temperaturas mais elevadas e menores índices pluviométricos, tiveram uma tendência a apresentarem um maior número de adesões no Programa Garantia Safra 2015/16, pois em muitos casos, nestes municípios, as únicas culturas plantadas pelo agricultor familiar para subsistência são justamente feijão e milho, culturas estas abrangidas pelo Programa Garantia Safra.

Para COSTA et al. (2014) a assistência Técnica e Extensão Rural (ATER), como um dos instrumentos de apoio ao desenvolvimento rural, deve ser executada mediante o uso de metodologias participativas, devendo seus agentes desempenhar um papel educativo, atuando como incentivadores e facilitadores de processos de desenvolvimento rural sustentável. Ao mesmo tempo, as ações de ATER devem privilegiar o potencial endógeno das comunidades e territórios, resgatar e interagir com os conhecimentos dos agricultores familiares e demais povos que vivem e trabalham no campo em regime de economia familiar, e estimular o uso sustentável dos recursos locais.

Técnicos de ATER juntamente com os produtores rurais devem elaborar técnicas de convívio com a seca com o intuito de garantir uma boa produção, mesmo em condições de cultivo em sequeiro no semiárido e assim não deixar o agricultor familiar refém do Programa Garantia Safra, visto que a intenção do programa não é manter essa renda para o agricultor todos os anos, o suporte financeiro deve ser disponibilizado somente em casos que, mesmo com todas as técnicas implantadas, for observada perda considerável de produção devido a efeitos climáticos. CESANO et al. (2011), indicam que experiências mostram que é preciso desenvolver, com urgência, políticas públicas inovadoras que consigam integrar o acesso à água com a disseminação de tecnologias de adaptação e de sistemas produtivos mais resilientes à seca.

Diante dos dados relatados, considerando as politicas públicas, é preciso pesquisas mais detalhadas para se constatar o real motivo dos relativos baixos números apresentados de DAP e aderidos no Garantia Safra em alguns municípios. Instituições de ATER, cooperativas, dentre outros órgãos juntamente com as Secretarias Municipais de Agricultura, sindicato dos trabalhadores rurais e associações dos respectivos municípios devem atuar juntos, afim de melhorias na assistência técnica, garantindo a todos os agricultores familiares a DAP e também a participação em politicas públicas, não só o garantia safra.

Esta ação conjunta deverá mapear detalhadamente todo o município, a fim de descobrir qual a real proporção de agricultores familiares que estão desassistidos pelas politicas públicas e programas sociais e não só efetuar o seu cadastramento, mas prestar uma assistência técnica contínua e de qualidade, com intuito de proporcionar melhorias a esta classe de trabalhadores que tanto contribui para 0 desenvolvimento de Brasil. 


\section{CONCLUSÕES}

- Considerando o número de estabelecimentos agropecuários pertencentes à agricultura familiar:

> Planalto, Bom Jesus da Serra e Cândido Sales se destacaram em número de DAPs, enquanto Encruzilhada, Caraíbas e Mortugaba apresentaram os menores valores.

> Bom Jesus da Serra, Planalto e Poções apresentaram os maiores valores proporcionais de agricultores aderidos no Programa Garantia Safra 2015/16 e os menores valores ficaram com os municípios de Encruzilhada, Ribeirão do Largo e Barra do Choça.

- Pesquisas mais detalhadas devem ser realizadas com o intuito de se constatar com mais clareza e realidade os valores de agricultores desassistidos pelas politicas públicas do meio rural, afim de melhorias na agricultura familiar.

\section{REFERÊNCIAS}

ABRAMOVAY, R. e VEIGA, E. da. Novas Instituições para o Desenvolvimento Rural: o caso do Programa Nacional de Fortalecimento da Agricultura Familiar (PRONAF). Brasília: IPEA: abril, 1998. 51p. (Texto para Discussão n.641). Disponível em: <http://repositorio.ipea.gov.br/bitstream/11058/2617/1/td 0641.pdf>. Acesso em 05 de fevereiro de 2016.

BLATT, N.; GONDIM, P. S. C. Territórios de identidade no estado da Bahia: uma análise da regionalização implantada pela estrutura governamental na perspectiva do desenvolvimento local e regional. Colóquio Baiano Espaços, Tempos e Representações: Abordagens Históricas e Geográficas. V. 1, N. 1. 2013. Disponível em: $<$ http://periodicos.uesb.br/index.php/coloquiobaiano/article/viewFile/2860/pdf 89>. Acesso em 05 de fevereiro de 2016.

BAHIA. Decreto $n^{\circ}$ 12.354, de 25 de agosto de 2010. Disponível em: $<$ http://governo-ba.jusbrasil.com.br/legislacao/1024959/decreto-12354-10>. Acesso em 12 de fevereiro de 2016.

BRASIL. Lei no 12.766, de 27 de dezembro de 2012. Disponível em: <http://www.planalto.gov.br/ccivil 03/ Ato2011-2014/2012/Lei/L12766.htm\#art6>.

Acesso em 12 de Fevereiro de 2016.

BRASIL. Lei no 12.512, de 14 de outubro de 2011. Disponível em: $<$ http://www.planalto.gov.br/ccivil 03/ ato2011-2014/2011/Lei/L12512.htm>. Acesso em 16 de fevereiro de 2016.

BRASIL. Lei no 11.326, de 24 de julho de 2006. Disponível em: $<$ http://www.planalto.gov.br/ccivil 03/ ato2004-2006/2006/lei/l11326.htm>. Acesso em 16 de fevereiro de 2016. 
BRASIL. Lei no 10.420, de 10 de abril de 2002. Disponível em: $<$ http://www.planalto.gov.br/ccivil 03/leis/2002/L10420a.htm>. Acesso em 12 de fevereiro de 2016.

BRASIL. Decreto no 1.946, de 28 de junho de 1996. Disponível em: $<$ http://www.planalto.gov.br/ccivil 03/decreto/D1946.htm\#art4§3b>. Acesso em 10 de fevereiro de 2016.

COSTA, A. H. S.; SILVA, S. S. da; LIMA, V. I. A.; PORDEUS, R. V.; PEREIRA, J. O. Diagnósticos Rurais Participativos nas Unidades de Produção Familiar no estado do Rio Grande do Norte Através da EMATER. Revista Verde, v 9. , n. 4 , p. 36 - 43, $2014 . \quad$ Disponível em: <http://www.gvaa.com.br/revista/index.php/RVADS/article/view/2984>. Acesso em 16 de março de 2016.

CESANO, D.; ROVERE, E. L. L.; OBERMAIER, M.; CORRAL, T.; SILVA; L. S. da; COELHO, N. S.; NEVES, C. G. As experiências da coalizão adapta sertão na disseminação de tecnologias e estratégias de adaptação à mudança climática para o agricultor familiar do semiárido Brasileiro. Revista Brasileira de Geografia Física, v. $06, \quad$ p. 1336-1350, $2011 . \quad$ Disponível em: $<$ http://www.revista.ufpe.br/rbgfe/index.php/revista/article/viewArticle/279>. Acesso em 21 de fevereiro de 2016.

EMB, Estatísticas dos Municípios Baianos, Território de Identidade Vitória da Conquista, $\mathrm{n}^{\circ} 20$, Salvador, v. 4, n . 1, 452 p., 2013.

FOGUESATTO, C. R.; MACHADO, J. A. D. A tomada de decisão dos jovens no processo migratório rural-urbano no Brasil: panorama entre 1970 e 2010. Revista Enciclopédia Biosfera. v. 11, n. 21, p. 2793-2802. 2015. Disponível em: $<$ http://www.conhecer.org.br/enciclop/2015b/multidisciplinar/a\%20tomada\%20de\%20 decisao.pdf>. Acesso em 25 de fevereiro de 2016.

IBGE (2016). Instituto Brasileiro de Geografia e Estatística. Sistema IBGE de Recuperação Automática - SIDRA. Disponível em: <http://www.sidra.ibge.gov.br>. Acesso em 10 de fevereiro de 2016.

LOBELL, D. B.; BURKE, M. B.; TEBALDI, C.; MASTRANDREA, M. D.; FALCON, W. P.; NAYLOR, R. L. Prioritizing climate change adaptation needs for food security in 2030. Science, v.319, p. 607-610, 2008. Disponível em: $<$ http://web.stanford.edu/ mburke/papers/Lobell et al Science 2008.pdf>. Acesso em 28 de fevereiro de 2016.

MARGULIS, S.; DUBEUX, C. B. S.; MARCOVITCH, J. (Ed.). Economia da mudança do clima no Brasil: custos e oportunidades. São Paulo: IBEP, 2010. Disponível em:

$<$ http://www.colit.pr.gov.br/arquivos/File/Publicacoes/Economia do clima.pdf $>$.

Acesso em 28 de fevereiro de 2016. 
MARTINS, M. A.; ALVALÁ, R. C. S.; TOMASELLA, J. Modelos de produtividade agrícola aplicados à agricultura de sequeiro: imitações e vantagens para avaliação de colapso de safras. Agropecuária Científica no Semiárido, v.10, n.4, p 41-48, 2014. Disponível em: <http://150.165.111.246/ojspatos/index.php/ACSA/article/viewFile/461/pdf-29>. Acesso em 30 de março de 2016.

MDA, Ministério do Desenvolvimento Agrário. Relatórios públicos de implementação do Garantia Safra. 2016. Disponível em: $<$ http://www.mda.gov.br/sitemda/secretaria/saf-garantia/relat\%C3\%B3rios-

p\%C3\%BAblicos-de-implementa\%C3\%A7\%C3\%A3o-do-garantia-safra>. Acesso em 01 de fevereiro de 2016.

MDA, Ministério do Desenvolvimento Agrário. ONU lança ano internacional da Agricultura Familiar nesta sexta-feira. 2014. Disponível em: $<$ http://www.brasil.gov.br/governo/2013/11/onu-lanca-ano-internacional-daagricultura-familiar-nesta-sexta-feira>. Acesso em 03 de março de 2016.

MEIRA, A. L.; SANTOS, P. R. P.; CONCEIÇÃO JÚNIOR, V.; OLIVEIRA, D. F. de; OLIVEIRA, H. H.; SOUZA, S. E. de. Uma abordagem sobre o papel da mulher na cadeia produtiva do café no município da Barra do Choça - Bahia. VIII Simpósio de Pesquisa de Cafés do Brasil. 25 a 28 de Novembro de 2013, Salvador - BA. Disponível em:

$<$ http://www.sbicafe.ufv.br/bitstream/handle/123456789/3720/78 VIII-SPCB2013.pdf? sequence $=1$ \&isAllowed $=y>$. Acesso em 14 de março de 2016. 